\title{
Consequences of mandated usage of innovations in organizations: developing an innovation decision model of symbolic and forced adoption
}

\author{
Sven Heidenreich ${ }^{1}$ (D) $\cdot$ Katrin Talke $^{2}$
}

Received: 21 March 2018 / Accepted: 21 February 2020 / Published online: 7 April 2020

(C) The Author(s) 2020

\begin{abstract}
In organizations, mandated adoption contexts are the rule rather than the exception. Individuals, who are denied the choice between adopting and rejecting an innovation, are more likely to engage in opposition behavior, particularly if the innovation conflicts with their held beliefs. Interestingly, neither the construct of forced adoption nor its consequences have received much research attention. To address this gap, we conduct a systematic literature review and provide theoretical rationales for the emergence of innovation resistance and opposition behaviors in organizations. We then develop an innovation decision model of individual adoption behavior that localizes negative outcomes of the secondary adoption process along the different process stages, providing insights into their emergence and potential consequences for the organization. Furthermore, we identify important avenues for future research and show how our innovation decision model can be used to advance theory development on forced adoption.
\end{abstract}

Keywords Forced adoption · Mandatory adoption · Secondary adoption process · Innovation resistance · Opposition behavior . Literature review

\section{Introduction}

The prior literature indicates that employee resistance and subsequent opposition is one of the biggest challenges in large-scale implementations of organizational innovations (Haddaraa and Moen, 2017; Lin et al. 2018). For instance, information systems literature reports failure rates of enterprise resource planning system implementations of approximately 50\% (Mahmud et al. 2017), with employees' innovation resistance reported as the most overwhelming reason for implementation failure (Lin et al. 2018; Kimberling 2014). Such implementation failures can ruin an entire business

\section{Sven Heidenreich}

sven.heidenreich@uni-saarland.de

Katrin Talke

katrin.talke@tu-berlin.de

1 Faculty of Human and Business Sciences, Saarland University, P.O. 151150, 66041 Saarbrücken, Germany

2 Technical University of Berlin, Straße des 17. Juni 135, Sekr. H 95 , 10623 Berlin, Germany operation and even endanger a whole company (Mahmud et al. 2017), as showcased by Fox Meyer, a 5-billion-dollar company, in 1996 (Haddara and Hetlevik 2016). However, even after implementation, innovations can still be underutilized or completely fail due to employees' opposition behavior (Raisian and Yahaya 2014). An example of such a postimplementation failure was reported by Bhattacherjee et al. (2013). Doctors at the Cedars-Sinai Medical Center in Los Angeles rebelled against a newly installed computerized physician order entry system and forced the complete withdrawal of the system after it had already been implemented in two-thirds of the 870-bed hospital.

These practical examples illustrate the nature and consequences of forced adoption. If in a mandated adoption context an organizational implementation decision violates the beliefs of individual employees, they may engage in various forms of opposition behavior, such as delaying the implementation misusing or sabotaging the innovation, or going on strike (e.g., Ajzen and Madden 1986; Scholl 1999). However, from an organizational perspective, mandated adoption contexts will be inevitable to implement innovations that are critical for the organization's success. Furthermore, since an organizational innovation is commonly referred to as "organizational 
change that embodies a new idea that is not consistent with the current concept of the organization's business" (Mezias and Glynn 1993p. 78), mandated use of innovations in times of rapid technology changes represents the rule rather than the exception (Jahanmir and Cavadas 2018). Hence, companies need to understand how forced adoption triggers innovation resistance and opposition behavior to effectively set up their internal marketing to reduce the probability of failure within implementation processes (Ram and Jung 1991; Varey 1995).

Over the past decades, several scholars have highlighted the importance of employee resistance and opposition behavior in mandatory adoption contexts and called for investigations into the concept of forced adoption (e.g., Ram and Jung 1991; Al-Sayed and Dugdale 2016). However, to date, theoretical and empirical insights are still scarce (Irawan et al. 2018; Samhan 2018), making forced adoption a less developed concept in organizational adoption research. At least three factors have hampered progress.

First, research widely assumes that the members of organizations have a choice between adopting and rejecting an innovation (e.g., Lapointe and Rivard 2005; Laumer and Eckhardt 2012). Only a handful of studies explicitly deal with the phenomenon of forced adoption (Cho and Chang 2008; Ram and Jung 1991). As a consequence, insights into the psychological processes triggered by forced adoption are scarce (Liu 2012). Moreover, to the best knowledge of the authors, there is no widely accepted theoretical anchor to draw from when explaining the consequences of forced adoption in organizations.

Second, those studies that deal with negative consequences of organizational adoption processes (e.g., Lapointe and Rivard 2005; Laumer and Eckhardt 2012) vary considerably with regard to the constructs considered and their conceptualization. As a consequence, a systematic overview of different types of employee reactions is missing, and concepts of employee resistance and opposition remain ambiguous in terms of their definitions, antecedents and consequences, just like the concept of forced adoption itself (Piderit 2000).

Third, most studies on individual adoption behavior in organizations do not follow a process approach (Frambach and Schillewaert 2002; Olshavsky and Spreng 1996). More specifically, they either separately focus on forced adoption as a contextual factor (mandatory versus voluntary contexts; Venkatesh and Davis 2000), the emergence of employee resistance to change or innovation (Kim and Kankanhalli 2009), the resulting opposition behavior of employees (Lapointe and Rivard 2005) or the potential consequences of implementation failure on success (Al-Sayed and Dugdale 2016). However, to fully understand why and at which point in time forced adoption triggers negative consequences, and how these are intertwined, an integrative perspective is indispensable (Gallivan 2001).

To close the aforementioned research gaps, we develop an integrative innovation decision model that provides rationales for how forced adoption affects individuals in organizations and triggers corresponding reactions. First, a systematic literature review on the concept of forced adoption of innovation is performed. Based on that review, prior findings are synthesized to derive conceptualizations of forced adoption and corresponding negative outcomes. We then draw on psychological reactance theory, decisional control theory and cognitive dissonance theory to explain how forced adoption affects employees in organizations, leading to innovation resistance and opposition behavior. Finally, we introduce an innovation decision model, which illustrates how innovation decisions proceed for individuals in organizations, why and at which stage different types of innovation resistance emerge, and how they encourage different forms of innovation opposition. We conclude with a comprehensive set of future research directions.

\section{Current state of research on the forced adoption of innovations}

\section{Methodological procedure used for the systematic literature review}

To systemize the current knowledge on forced adoption, a systematic review of the literature was conducted, following procedures suggested by Bartels and Reinders (2011). First, a database search was performed, using access to three different databases: ScienceDirect, Emerald Management Xtra and EBSCO. All articles available through May 2019 were included. The systematic review followed a multistage approach to narrow down the most relevant literature on forced adoption. The first stage encompassed an automated abstract search in the relevant databases with "forced adoption" as focal search term. As some studies refer to forced adoption using the labels of "mandatory adoption" (Hwang et al. 2017; Venkatesh and Davis 2000), "authority adoption" or "authority decision" (Gallivan 2001; Zaltman and Wallendorf 1983), and "contingent adoption" or "contingent decision" (Frambach and Schillewaert 2002), we also included these search terms to broaden our results. We additionally included a contextspecific search term, namely, "innovation" using the "AND" condition. Furthermore, we also included "change" as an additional context-specific search term using the "OR" condition to cover the broad research stream on organizational resistance to change induced by innovations (Choi 2011; Pardo del Val and Martínez Fuentes 2003). Based on this automated abstract search, the full papers were checked for content relevance in the second stage. After checking for overlaps of the search results using the databases in the third stage, 14 articles were included in the relevant set. We then performed a crossreference search of the articles found by using the first three stages, leading to an additional 22 articles that were deemed relevant, leading to 36 articles in total. Appendix, Table 2 
provides an overview of the characteristics of the 36 articles included in the final sample (Table 1).

\section{Primary versus secondary adoption of innovations}

An initial assessment of the 36 articles and their crossreferences showed that a substantive amount of research widely neglects individual innovation adoption decisions but rather focuses on the firm-level decision to adopt or reject change in general (Barr et al. 1992; Jones et al. 2005) or innovations in particular (Al-Sayed and Dugdale 2016). However, some studies focus on the employee level and shed light on the evolution of resistance to change in general (Herold et al. 2007; Oreg 2003) and resistance to innovations in particular (Kim and Kankanhalli 2009; Lapointe and Rivard 2005). Nevertheless, these studies often decouple the employeelevel adoption process from the firm-level and thus do not account for the mandated adoption context and its consequences for individual behavior (Gallivan 2001). Other studies differentiate between a primary adoption process and secondary adoption process (Leonard-Barton and Deschamps 1988; Kishore and McLean 2007).

The primary adoption process captures the consensusbased initial adoption at the organization level, which is often solely decided by the management. The secondary adoption process, in contrast, captures individual adoption at the employee level in a mandated adoption context (Perera et al. 2003). However, except for a few rare exceptions, studies shedding light on the secondary adoption process are still lacking (Gallivan 2001; Irawan et al. 2018). Accordingly, the secondary adoption process is often referred to as the "black box" (Gallivan 2001), making the concept of forced adoption a less developed construct in organizational adoption theory. As a consequence, several studies have called for more research into the nature and consequences of forced adoption in organizations (Brown et al. 2002; Xue et al. 2011).

\section{Forced and symbolic adoption of innovations}

The systematic literature review further indicates that only 10 of the 36 articles exclusively focus on the forced adoption of innovations (e.g., Cho and Chang 2008; Ram and Jung 1991), while the rest discuss forced adoption only in passing (e.g., Leonard-Barton 1987; Marakas and Hornig 1996; Rawstorne et al. 2000). However, it should be noted that the concept of mandatory adoption (the same accounts for authority/contingent adoption, leading to its synonymous use in this manuscript) differs from that of forced adoption.

Mandatory adoption usually refers to the common situation in organizations that a decision unit has decided to adopt and implement an innovation, irrespective of whether individual employees are willing to use it (Brown et al. 2002; Venkatesh and Davis 2000). Forced adoption, on the other hand, considers the individual perspective in the context of mandatory adoption, and refers to a situation, where an individual employee is unwilling to adopt an innovation but has to do it anyway because he or she are required to do so (Cho and Chang 2008; Kumar et al. 2018).

The small yet existent deviation between these definitions is important for the following reasons. In a mandatory adoption context, employees' freedom of choice is principally restricted (Deci and Ryan 2000). If the innovation conforms with the employees' attitudes and beliefs, such restrictions should not be detrimental, as the employee would adopt the innovation voluntarily. In contrast, if the employee is not willing to adopt the innovation, the mandated adoption would be perceived as being forced by the organization. As a consequence, and in line with self-determination theory (Deci and Ryan 2000), this will prompt negative reactions as the mandated behavior conflicts with the employees' attitudes, leading to inner tensions. Hence, we propose to differentiate between the context (i.e., mandatory adoption) and the outcome for the employee, which can be either congruent (i.e., symbolic adoption) or incongruent (i.e., forced adoption) with the organizational mandate.
Table 1 Methodological procedure of systematic literature review

\begin{tabular}{|c|c|c|c|c|}
\hline Process & $\begin{array}{l}\text { Science } \\
\text { Direct }\end{array}$ & emerald & $\begin{array}{l}\text { Ebsco } \\
\text { Host }\end{array}$ & $\begin{array}{l}\text { methodological } \\
\text { approach }\end{array}$ \\
\hline $\begin{array}{l}\text { (“forced adoption" OR "mandatory adoption" OR } \\
\text { "authority adoption" OR “authority decision" OR } \\
\text { "contingent adoption" OR "contingent decision") } \\
\text { AND (innovation OR change) }\end{array}$ & 30 & 11 & 86 & $\begin{array}{l}\text { automated abstract } \\
\text { search }\end{array}$ \\
\hline relevant set literature review (single) & 5 & 2 & 9 & $\begin{array}{l}\text { manual full paper } \\
\text { check }\end{array}$ \\
\hline relevant set literature review (combined) & 14 & & & $\begin{array}{l}\text { manual check for } \\
\text { overlaps }\end{array}$ \\
\hline additional analysis & +22 & & & $\begin{array}{l}\text { manual search by } \\
\text { cross reference } \\
\text { check }\end{array}$ \\
\hline extended relevant set & $\sum 36$ & & & \\
\hline
\end{tabular}


While symbolic adoption means that employees voluntarily adopt the innovation, the term "symbolic" underlines that the outcome in mandatory adoption contexts is in any case predetermined (modified definition based on Karahanna and Agarwal 2006; Klonglan and Coward 1970). Forced adoption means that employees are coerced to adopt an innovation even though they personally would rather resist than accept it.

Following these definitions, the presence of employee resistance to innovations represents the key reason for turning the mandated usage of innovations into forced adoption, potentially leading to negative consequences for the implementation process. While we have clarified the conceptualizations of mandatory and forced adoption, a clear and distinct definition for employee resistance to innovation in organizational contexts is still missing.

\section{Passive and active innovation resistance}

With respect to employee resistance to innovation, conceptualizations found within the literature review vary considerably. Some scholars conceptualize innovation resistance as a result of employees' inclinations to resist change in general (Costa et al. 2013; Xue et al. 2011), to insist on keeping their status quo (Kim and Kankanhalli 2009; Kim and Chung 2017), or both in combination (Lin et al. 2018; Samhan 2018). Hence, this line of research understands resistance to innovation as a generic predisposition that is rooted in employee characteristics. Another line of research understands employee resistance to innovation as negative attitude formation that is rooted in the evaluation of the innovation's characteristics (Liu 2012; Brown et al. 2002). Finally, some researchers combine these conceptualizations and describe different types of employee resistance to innovations (Ram and Jung 1991; Cho and Chang 2008). In line with the latter research stream and established conceptualizations of innovation resistance in consumer contexts (Claudy et al. 2015; Talke and Heidenreich 2014), we propose to distinguish passive innovation resistance from active innovation resistance.

Passive innovation resistance represents a generic predisposition to resist innovations that is derived from the degree of change entailed in the adoption of the innovation (Heidenreich et al. 2016; Heidenreich and Spieth 2013). It evolves from individuals' inclination to resist change (Oreg 2003) and their satisfaction with the status quo (Heidenreich and Handrich 2015) in the moment of awareness, which separately or in combination induces a generic disposition to resist innovations (Heidenreich and Kraemer 2016; Labrecque et al. 2016).

Active innovation resistance represents an attitudinal response that evolves from innovation-specific factors during the evaluation of the innovation (Labrecque et al. 2016; Talke and Heidenreich 2014). More specifically, individuals compare their perception of innovation attributes with their expectations. If deviations exceed an adopter-specific threshold, then functional and psychological barriers arise, leading to negative attitude formation (Talke and Heidenreich 2014).

While the types of innovation resistance that individuals may encounter in voluntary adoption scenarios do not differ from those in a mandated adoption context, the consequences of innovation resistance likely differ significantly between these scenarios (Ram and Jung 1991). However, because prior research has not explicitly accounted for mandated contexts when examining employee resistance to innovations, it still lacks common typologies for consequences of passive and active innovation resistance under mandated usage.

\section{Passive and active innovation opposition}

In voluntary adoption scenarios, individuals can regularly exert full control over their adoption decisions (Ram and Jung 1991; Reinders et al. 2008). When individuals do not feel like dealing with an innovation or are not convinced of its superiority, they have the freedom to postpone or terminate the decision process at any stage (for a detailed description, see Talke and Heidenreich 2014). Thus, if passive or active innovation resistance is high, individuals are able to reject an innovation and may never be confronted with it again (Talke and Heidenreich 2014). This can also happen to products or services that were previously adopted but that didn't turn out to be useful, are no longer wanted or needed (Lehmann and Parker 2017).

In mandated adoption contexts, however, individuals with high levels of passive and active innovation resistance have no other choice but to adopt and use the innovation (Cho and Chang 2008). In particular, if an innovation is considered critical for the success of an organization, division, department, or team, the decision to implement that innovation will be made by the management. In these cases, the organization member is expected to adopt the innovation and work with it, even if he or she would have rejected the innovation in the first place. Hence, despite the intention to reject an innovation, forced adoption becomes the predefined outcome of the secondary adoption process. As a consequence, the organization members can be expected to engage in different forms of adverse behavior to deal with the current situation.

These forms of adverse behavioral responses by organization members are labeled opposition to innovation (Hirschheim and Newman 1988; Markus 1983). As indicated by our literature review, prior research does not introduce a common typology of opposition behavior, but points to a variety of different behaviors employees could engage in, ranging from slow performance and absenteeism (Bhattacherjee et al. 2013) to sabotage and strikes (Lapointe and Rivard 2005). To provide a 
systematic overview of opposition behavior that may emerge in response to forced adoption, we propose to adapt the established framework of defense mechanisms introduced by Bovey and Hede (2001) and differentiate between active innovation opposition and passive innovation opposition.

Passive innovation opposition encompasses unconscious defense mechanisms that arise involuntarily when individuals feel threatened by an innovation they are expected to adopt (Andrews et al. 1993). As a result of passive opposition, energy is directed elsewhere, away from work-related tasks (Oldham and Kleiner 1990). Passive opposition may already arise in the early stages of the secondary adoption process and may manifest in dissatisfaction, lack of motivation or low organizational commitment. If employees are unable to resolve their perception of being threatened by an innovation, these rather mild forms of opposition may grow more destructive over time. In the most extreme cases, passive innovation opposition may lead to a complete loss of organizational commitment and mental dismissal (Faragher et al. 2005; Tatsuse and Sekine 2013). Several scholars consider passive innovation opposition to be the main cause of inefficiency, in terms of both people and organizations (De Board 2014).

Active innovation opposition includes different forms of behaviors individuals deliberately chose to turn down an unwanted innovation. Active opposition can manifest in overt and covert forms (Bovey and Hede 2001). Forms of covert innovation opposition encompass hidden behaviors designed to maintain previous working routines and avoid the new ones (Bovey and Hede 2001). A sales manager could, for example, focus his sales efforts on known products while neglecting to promote a new product to his customers. Apart from avoiding tasks associated with the use of an innovation, organization members can also delay their execution (Lapointe and Rivard 2005). They may, for example, circumvent the use of an innovation by making excuses (Xue et al. 2011), or completely withdraw from work by calling in sick (Bhattacherjee et al. 2013). More extreme forms of covert opposition include changing the job within the firm or terminating their employment altogether (Haddara and Moen, 2017).

Overt innovation opposition encompasses all types of openly expressed behaviors intended to obstruct, cancel or reverse the implementation of an innovation (Bovey and Hede 2001). Organization members may openly oppose an innovation by publicly expressing their concerns (Mahmud et al. 2017; Ram and Jung 1991), by convincing other employees of their arguments, and by mobilizing like-minded colleagues to join their cause and rally against the innovation (Lapointe and Rivard 2005). They may also insult or mob colleagues who support the innovation (Lapointe and Rivard 2005). Overt opposition can also take even more destructive forms like sabotage (Brown et al. 2002), infighting, threats, boss-napping, strikes, or collective boycotts (Lapointe and Rivard 2005; Laumer and Eckhardt 2012).

While prior research underlines the relevance of opposition behaviors resulting from forced adoption, theoretical rationales that might explain the transformational mechanisms from passive or active resistance to opposition behavior are scarce. However, several studies provide indications that perceptions of lost control (Reinders et al. 2008), the emergence of psychological reactance (Liu 2012; Saeed and Abdinnour 2013), the strive to resolve the unpleasant state of cognitive dissonance (Karahanna and Agarwal 2006) might prove relevant in this context.

\section{Psychological reactance and decisional control theory}

To develop a theoretically substantiated explanation of the transformation of innovation resistance into opposition behavior we integrate insights from decisional control theory, psychological reactance theory, and cognitive dissonance theory.

According to decisional control theory (Mallen 1970), the extent of choice on means and goals that a person has in a situation is significantly reduced when individuals are no longer able to make decisions for themselves (Hui and Toffoli 2002; Botti et al. 2003). Forcing employees to use an innovation thus reduces their freedom to organize their work environment for themselves, most likely reducing their perceptions of decisional control (Reinders et al. 2008). As a consequence, an unpleasant state of dissonance occurs because the employee would decide in favor of innovation rejection but is not allowed to do so.

A similar line of thought is brought forward by psychological reactance theory (Brehm 1966). Forced adoption threatens an employee's autonomy, resulting in a motivational state that focuses on avoiding that threat (i.e., using the mandated innovation) and engaging in unthreatening behaviors (i.e., using the option in place) (Clee and Wicklund 1980; Johnson et al. 2008). Hence, the option that is to be replaced becomes more appealing, and the innovation that is mandated becomes less appealing (Reinders et al. 2008; Saeed and Abdinnour 2013). As a consequence, an unpleasant state of dissonance occurs because the employee wants to hold onto the option in place but is forced to adopt the innovation.

Social psychological research uses cognitive dissonance theory (Aronson 1969; Festinger 1957) to describe such unpleasant states of dissonance that occur whenever an individual simultaneously holds two cognitions that are psychologically inconsistent. When the order to adopt an innovation differs from an individual's disposition (i.e., passive innovation resistance) or attitude (i.e., active innovation resistance), 
dissonance will drive the individual to react. The literature has discussed a wide range of adaptive strategies (Leonard et al. 1999). However, when individuals are constrained and feel unable to control their own decisions, negative reactions are very likely to occur (Ajzen and Madden 1986; Scholl 1996, 1999). According to Brehm (1966), individuals can engage in either directly or indirectly observable behavior to reduce cognitive dissonance.

In the context of forced adoption in organizations, employees with high levels of innovation resistance will most likely engage in passive and covert (active) opposition behavior (not directly observable) or overt (active) opposition behavior (directly observable) to reduce cognitive dissonance due to the forced adoption. However, social psychological research suggests that employee resistance might increase over time if pressure to use the innovation continues (Abramson et al. 1978). Hence, when innovation adoption is forced, initial innovation resistance likely increases throughout the decision and implementation process, and thus, the transformational mechanisms into opposition behavior might also vary throughout the stages of the secondary adoption process in organizations. To better understand the consequences of forced adoption and the transformational mechanisms described above, prior research has called for the development of an innovation decision model for the secondary adoption process (Gallivan 2001). Yet, research on innovation decision models in the organizational context almost exclusively pertains to the primary adoption process (e.g., Cooper and Zmud 1990). Furthermore, the rare exceptions that strive to shed light on the secondary adoption process (e.g., Gallivan 2001) focus on the antecedents and consequences of employee adoption behavior rather than the process itself. Building on the theoretical insights derived from our literature review in this chapter, we strive to develop an innovation decision model of the secondary adoption process for mandatory contexts in organizations to deliver the needed approach. More specifically, for each construct identified as relevant in mandatory adoption contexts, we use the unambiguous definitions and corresponding theoretical rationales for their occurrence derived from our literature review, to set up an integrative innovation decision model. Within the innovation decision model, we then localize all outcomes identified in the literature review along the different stages of the secondary adoption process and illustrate how innovation decisions proceed for individuals in organizations, why and at which stage negative outcomes emerge, and how they encourage different forms of innovation opposition.

\section{Proposing an innovation decision model for the secondary adoption process in mandatory contexts}

An innovation decision model of the secondary adoption process in organizations will provide a structure of the negative consequences of forced adoption and illustrate their escalation over time. Consumer behavior research has a long tradition of discussing innovation decision models for individual adoption behavior (Labay and Kinnear 1981; Nabih et al. 1997; Rogers 2003). Existing models differ in terminology and phasing (e.g., Nabih et al. 1997; Talke and Heidenreich 2014). Still, their general structure is commonly based on the innovation decision model by Rogers (2003) and includes two central components; the decision-making process itself and positive and negative outcomes that are localized along the adoption process stages.

However, these models need to be modified to acknowledge organization members' lack of freedom when making an adoption decision. Instead of the five stages brought forward by Rogers (2003), we propose to consider only three stages: (1) knowledge, (2) persuasion and (3) implementation (please see fig. 1). The mandated context makes the stages of decision and confirmation redundant, since employees can neither decide whether to adopt or reject the innovation in the first place (decision stage) nor can they reverse previous adoption decisions (confirmation stage).

To illustrate how the mandated context affects the emergence of negative consequences throughout the secondary adoption process, we discuss each stage. While we touch upon the positive outcomes of the three stages (passive acceptance, active acceptance, symbolic adoption), we describe the negative outcomes (passive resistance, active resistance, forced adoption) in greater detail and show how they might lead to passive and active forms of opposition behavior throughout the decision process. The theoretical rationales on negative outcomes derived from our innovation decision model are then summarized in solid propositions about the relationships between these core constructs, and converted into a conceptual process model of forced adoption (Burgelman 1983;; Keats and Bracker 1988).

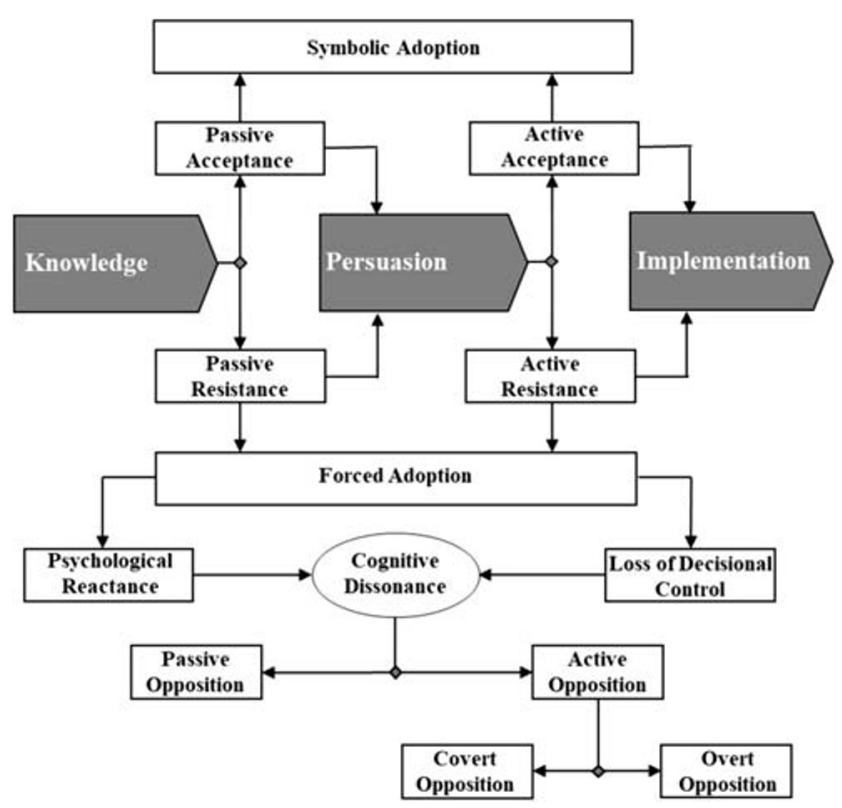

Fig. 1 Innovation decision model for mandatory contexts 


\section{Knowledge stage}

The knowledge stage describes the initial confrontation of an organization member with an innovation (Zaltman and Wallendorf 1983). This confrontation might be due to a random perception at work. However, in an organizational context, an individual's perception of an innovation will often be directed by internal marketing (Varey 1995), for example, by an announcement that there soon will be a new accounting software, a new manufacturing robot or new guidelines for dealing with customers (Ram and Jung 1991). As a result of this stage, organization members might experience passive acceptance, which describes the initial subconscious willingness to deal with the innovation more closely (Nabih et al. 1997; Talke and Heidenreich 2014). In this case, the decision process will continue to the next stage of "persuasion". Consequently, it is presumed that passive acceptance leads to a first trial and ultimately, if the trial is successful, to symbolic adoption of the innovation.

The other outcome of this stage is passive resistance, which describes a subconscious and unsubstantiated aversion to an innovation-related change (Nabih et al. 1997; Talke and Heidenreich 2014). Organization members with high levels of passive resistance are generally unwilling to thoroughly evaluate an innovation, its properties and potential advantages (Nabih et al. 1997). Whether and to what degree passive innovation resistance arises mainly depends on adopter-specific factors (Heidenreich and Kraemer 2015; Talke and Heidenreich 2014). In adoption research, several sociodemographic characteristics have been studied (Im et al. 2003; Tornatzky and Klein 1982). However, meta-analyses show that sociodemographic factors, such as age, gender and education, do not explain much of the course of decision processes, whereas select psychographic factors do (Arts et al. 2011). More specifically, both consumer behavior research (e.g., Heidenreich and Handrich 2015) and organizational research (e.g., Kim and Kankanhalli 2009) show that passive innovation resistance is primarily determined by an individual's inclination to resist change in general and his or her satisfaction with the current status quo. If, for example, an employee is principally IT-averse and satisfied with the data processing software in use, a new software will most likely be perceived as a disturbance of proven and tested workflows, regardless of the potential benefits (Gersick and Hackman 1990).

If the level of passive innovation resistance stays below an individual-specific tolerance threshold, the organization member most likely engages in further information processing to reach a specific judgment (Laumer and Eckhardt 2012; Talke and Heidenreich 2014). In this case, the decision process is continued. However, once passive resistance exceeds that threshold, the organization member will develop a subconscious negative attitude toward the innovation to maintain the status quo (Bagozzi and Lee 1999; Talke and Heidenreich 2014).
While consumers would most likely terminate the decision process at this point (Talke and Heidenreich 2014), organization members will be expected to adopt the innovation. Hence, the individual employee is forced to deal with the innovation in more detail, whether he or she likes it or not. At best, the decision-making process is resumed with an open mind. In the more likely and worse case, however, the organization member persists on his or her level of passive resistance and remains reluctant to occupy him- or herself with the proposed innovation. Due to the mandatory context, organizational expectations and employee preferences become incongruent in this early stage of the process. As a consequence of being denied decisional autonomy, employees likely encounter a loss of decisional control while simultaneously a certain psychological reactance against the innovation develops, both leading to cognitive dissonance. With rising degrees of cognitive dissonance in the early stage of the adoption process, first instances of opposition behavior may emerge, most likely passive forms. Forms of passive opposition may include directing less mental energy toward innovation-related tasks (Bovey and Hede 2001), as well as a decrease in motivation, satisfaction with the job, and organizational commitment. The above made considerations lead to the following propositions:

P1: Passive innovation resistance in mandatory adoption contexts increases cognitive dissonance

P2: Psychological reactance mediates the effect of passive innovation resistance on cognitive dissonance

P2a: Passive innovation resistance is positively related to psychological reactance

P2b: Psychological reactance is positively related to cognitive dissonance

P3: Loss of decisional control mediates the effect of passive innovation resistance on cognitive dissonance

P3a: Passive innovation resistance is positively related to loss of decisional control

P3b: Loss of decisional control is positively related to cognitive dissonance

P4: Cognitive dissonance that emerges at the knowledge phase leads to first instances of opposition behavior, most likely passive opposition behavior

\section{Persuasion stage}

At the persuasion stage, organization members develop specific attitudes toward the innovation (Nabih et al. 1997). In addition to initial engagement with the innovation, employees continuously process information, which was either actively searched for or provided by other organization members (Pohl 1996) or internal marketing (Piercy and Morgan 1991). The interplay of adopter-specific and situation-specific factors determines individuals' expectations of a subjectively optimal 
innovation. Based on a decisive new product evaluation, the employees then assess the potential fit between their own expectations and the perceived innovation characteristics. In the case of a fit or positive deviations, the product evaluation will lead to positive attitude formation and thus active innovation acceptance. In this case, symbolic adoption would be reinforced, and the decision process will continue to the next stage "implementation". If the new product evaluation leads to negative deviations between an organization member's own expectations and the perceived innovation characteristics, barriers to innovation will arise (Talke and Heidenreich 2014).

Functional barriers evolve as soon as organization members perceive a product attribute as inadequate or dysfunctional for their personal needs and usage expectations (Talke and Heidenreich 2014). This might be the case if an innovation is perceived as overly complex or as lacking superior performance over existing alternatives (Laukkanen 2016; Laukkanen et al. 2008). Psychological barriers evolve as soon as the innovation conflicts with an organization member's social values, norms, or individual usage patterns or if its application is considered to be too risky (Ram and Sheth 1989; Talke and Heidenreich 2014). Based on the level of innovation-specific barriers, organization members develop negative attitudes toward the innovation; this is commonly referred to as active innovation resistance. Unlike passive innovation resistance, active resistance represents a deliberate form of resistance since it is based on a negative assessment of an innovation (Nabih et al. 1997). In the presence of active innovation resistance, organization members are likely to develop a strong intention to reject the innovation. However, due to the mandatory context, rejection is impossible, and thus, forced adoption is the only possible outcome. As a consequence, both the feeling of a certain loss of decisional control as well as psychological reactance against the innovation are reinforced, further increasing the level of cognitive dissonance.

As described above, passive opposition can occur in the knowledge stage if organizational members experience high levels of cognitive dissonance due to a forced adoption of an innovation in spite of passive innovation resistance. Likewise, in the persuasion stage, active innovation resistance reinforces the unpleasant states of cognitive dissonance making adaptive strategies, such as passive opposition behavior, even more likely to emerge in order to reduce cognitive dissonance. Furthermore, social psychological research implies that opposition behavior increases over time if pressure continues (Abramson et al. 1978). Hence, when organizational pressure for adoption continues throughout the decision process, passive opposition is either likely to take more severe forms (e.g., loss of organizational commitment or mental dismissal) or transform into active opposition (Bovey and Hede 2001). In the persuasion stage, where the innovation is not yet fully in use, covert forms of active opposition behavior are most likely to emerge as a result of cognitive dissonance. Employees engage in different types of hidden behavior, which help them maintain previous behaviors and to neglect the use of the innovation (Bovey and Hede 2001), alleviating the unpleasant feeling of cognitive dissonance. They may, for example, try to avoid using the innovation by making excuses or completely withdraw from work by reporting sick, changing jobs within the firm, or terminating their employment. Collectively, the aforementioned arguments lead to the following propositions:

P5: Active innovation resistance in mandatory adoption contexts increases cognitive dissonance

P6: Psychological reactance mediates the effect of active innovation resistance on cognitive dissonance

P6a: Active innovation resistance is positively related to psychological reactance

P6b: Psychological reactance is positively related to cognitive dissonance

P7: Loss of decisional control mediates the effect of active innovation resistance on cognitive dissonance

P7a: Active innovation resistance is positively related to loss of decisional control

P7b: Loss of decisional control is positively related to cognitive dissonance

P8: Cognitive dissonance that emerges or is increased at the persuasion stage leads to more severe forms of passive opposition behavior and may even transform into active opposition behavior. At this stage, we expect different forms of active, covert opposition as the most likely outcome.

\section{Implementation stage}

At the implementation stage, the employees are confronted with the innovation directly as it is fully rolled out and thus ready to become the new standard for every employee. As a result, the employee has no choice but to use the innovation regularly. Since confrontation with the innovation is thus inevitable, some employees are forced to carry out work routines that are psychologically inconsistent with their unfavorable predisposition (passive innovation resistance) and negative attitudes (active innovation resistance), leading to the most unpleasant state of cognitive dissonance. Organization members, who developed strong resistance levels in the early stages of the decision process and maintained them throughout the entire process, are more likely to perceive forced adoption as extremely stressful due to conflicts with their own beliefs (Liu 2012; Ram and Jung 1991) and due to feelings of helplessness and lost control over their own actions (Scholl 1996, 1999). Initially, these members' innovation resistance might have led to passive opposition in the form of dissatisfaction, declining motivation and decreasing commitment (Cho and Chang 2008). However, over time, the consequences are likely to become more extreme. Depending on 
the individual's personality and the degree of support in the work environment, reactions may take on overt forms of active opposition behavior. Such behaviors may encompass publicly expressing concerns or mobilizing like-minded colleagues to cancel or reverse the implementation of an innovation (Kim and Kankanhalli 2009) or even more destructive forms, like infighting, threats, boss-napping, strikes, collective boycotts or sabotage (Lapointe and Rivard 2005; Laumer and Eckhardt 2012). In the most dramatic case, the enduring psychological burden of being forced to use an innovation might sicken the organizational member and even lead to burn-out or early retirement from employment (Faragher et al. 2005; Tatsuse and Sekine 2013). These considerations lead to the last proposition, given below:

P9: Cognitive dissonance that is increased at the implementation stage leads to the most intense forms of passive and active opposition behavior. At this stage, we expect different forms of active, overt opposition as the most likely outcomes.

In conclusion, negative reactions triggered by forced adoption in the implementation stage, at a minimum, hamper progress in large-scale implementations of organizational innovations, but in severe cases, might also lead to a complete withdrawal and thus implementation failure at the organizational level.

From a managerial perspective, it thus seems of utmost importance to use internal marketing to help overcome employee resistance to innovation in mandated usage scenarios (Varey 1995). Previous research within this respect has shown that internal marketing is an effective measure "to overcome organizational resistance to change and to align, motivate and integrate employees towards the effective implementation of corporate and functional strategies" (Rafiq and Ahmed 1993 p. 222). However, using internal marketing to educate, motivate and align employees towards institutional objectives during innovation implementation (Winter 1985), requires better knowledge on when and how mandated usage transforms into forced adoption with opposition behavior as the detrimental consequence. The presented innovation decision model of the secondary adoption process provides internal marketers with first insights into which circumstances mandated usage transforms into forced adoption as well as when and how negative outcomes at employee level emerge as consequences. The corresponding process model additionally provides internal marketers with a deeper understanding of the corresponding chain of effects. Both models collectively should help companies in selecting effective internal marketing measures to reduce the occurrence of forced adoption and thus in overcoming one of the biggest challenges in the large-scale implementation of organizational innovations (Haddaraa and Moen, 2017; Lin et al. 2018).

From a theoretical perspective, the presented innovation decision model represents the first attempt to integrate scattered findings on previously separated concepts of forced adoption, employee resistance to innovation and opposition behavior by drawing on theory related to psychological reactance, decisional control and cognitive dissonance. Unlike the innovation decision models used in consumer research (Rogers 2003; Talke and Heidenreich 2014), this innovation decision model puts particular emphasis on the scenario of forced adoption to illustrate how individuals react when they are not given the choice between adoption and rejection. Hence, the innovation decision model presented in this manuscript may serve as a conceptual framework for future marketing and organizational research striving to advance theory on forced adoption (please see fig. 2).

\section{Advancing theory on forced adoption}

Following Dubin's (1978) model of theory building, advancing theory in organizational research requires the specification of "(a) the constructs or variables of interest, (b) congruence, that is, the set of laws of relationship among constructs or variables, (c) the boundaries within which the laws of relationship are expected to operate, and (d) the contingency hypotheses within which the integrity of the system is maintained but in a markedly different condition" (Barreto 2010 p. 264). Our innovation decision model represents a first step toward building common theoretical ground for forced adoption that specifies the constructs of interest, their relations and their boundary and contingency conditions. However, empirical examinations still need to be carried out to validate the theoretical propositions made and to extend their assumptions by generating new insight into the secondary adoption process of employees in mandatory contexts. In the following, we thus elaborate on how forced adoption can be established as a clear and independent research stream by examining the nomological network in which it is situated (e.g., antecedents, outcomes, and mediating and moderating variables; Foss and Saebi

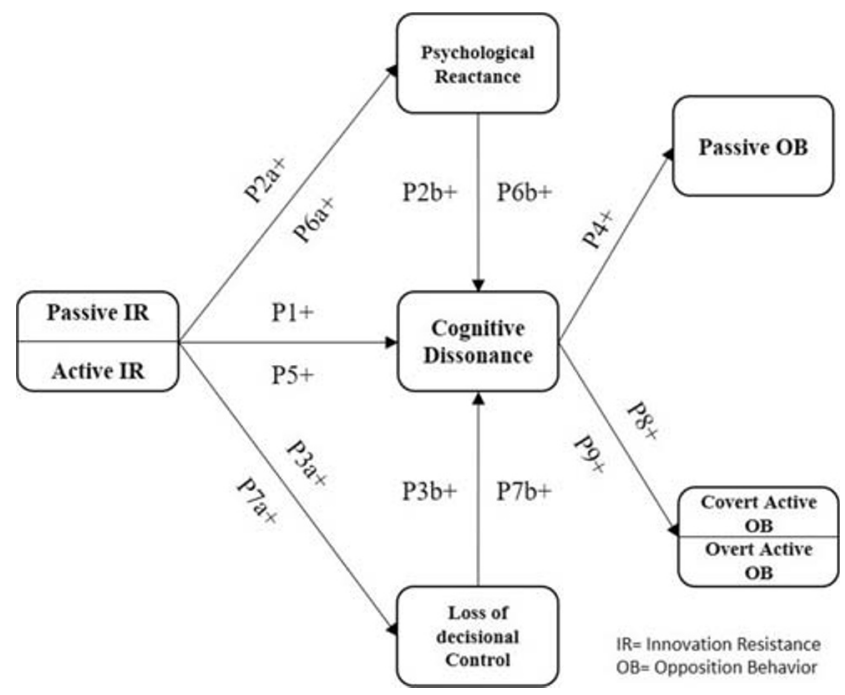

Fig. 2 Conceptual process model of forced adoption 
2017). The corresponding potential future research avenues are laid out in 4 areas: (1) construct, (2) congruence, (3) contingency and (4) boundary conditions (please see fig. 3).

\section{Addressing research gaps related to the core constructs}

To advance theory on forced adoption, future research should be clear regarding the core constructs, namely, forced adoption as well as innovation resistance and opposition behavior. To disentangle the concepts of mandatory adoption and forced adoption (Brown et al. 2002; Venkatesh and Davis 2000), we propose two distinct definitions. We define forced adoption as a potential outcome of the mandated usage of innovations in organizations, where employees are forced to adopt innovations even though they personally would rather resist than accept them. Hence, we explicitly separate the mandated context from forced adoption as potential result during the secondary adoption process.

In addition, the innovation decision model provides theoretical rationales indicating under which circumstances forced adoption emerges. According to our model, the prerequisite of forced adoption is mandated usage ordered by management and, at the same time, the emergence of passive and/or active innovation resistance at the employee level. If no resistance is present, symbolic adoption rather than forced adoption will be the consequence of the mandated use. While the conceptualization of forced adoption thus seems clear, evidence is still lacking in terms of determining variations in individual threshold levels of passive and active innovation resistance, at which employees perceive mandated adoption as forced rather than as symbolic. In addition, it remains unclear how organizations should manage the implementation of a mandatory innovation using, for example, internal marketing campaigns (Rafiq and Ahmed 1993). Clearly, the goal should be to alleviate feelings of pressure along the implementation process, starting with the initial announcement and continuing throughout the process. In experimental settings, future research may test how communicating different levels of constraint (Fidler and Johnson 1984), such as disconnecting disobedience from punishment (Xue et al. 2011), affect employee perceptions of forced adoption.

With respect to innovation resistance, our literature review shows that the corresponding definitions vary considerably among prior studies. To work towards scientific consensus, we propose to adapt the well-established concepts of passive and active innovation resistance (Talke and Heidenreich 2014) from the consumer context to the organizational context. In our innovation decision model, we further disentangle these often mingled constructs and their consequences by referring to their allocation along the stages of the secondary adoption process and by providing underlying theoretical rationales for their emergence. While it seems reasonable to expect that the psychological mechanisms that lead to innovation resistance should be identical for consumers and employees, future research may test this proposition in mandatory contexts using the constructs of passive innovation resistance (Heidenreich and Handrich 2015) and active innovation resistance (Joachim et al. 2018).

Based on our literature review we have learned opposition behavior as a response to forced adoption covers a broad spectrum, ranging from rather mild (Bhattacherjee et al. 2013) to destructive forms (Lapointe and Rivard 2005). To provide a common typology of innovation opposition, we adapt Bovey and Hede's (2001) framework of defense mechanisms to the context of forced adoption and differentiate active from passive forms. Future research might build on that typology, and by
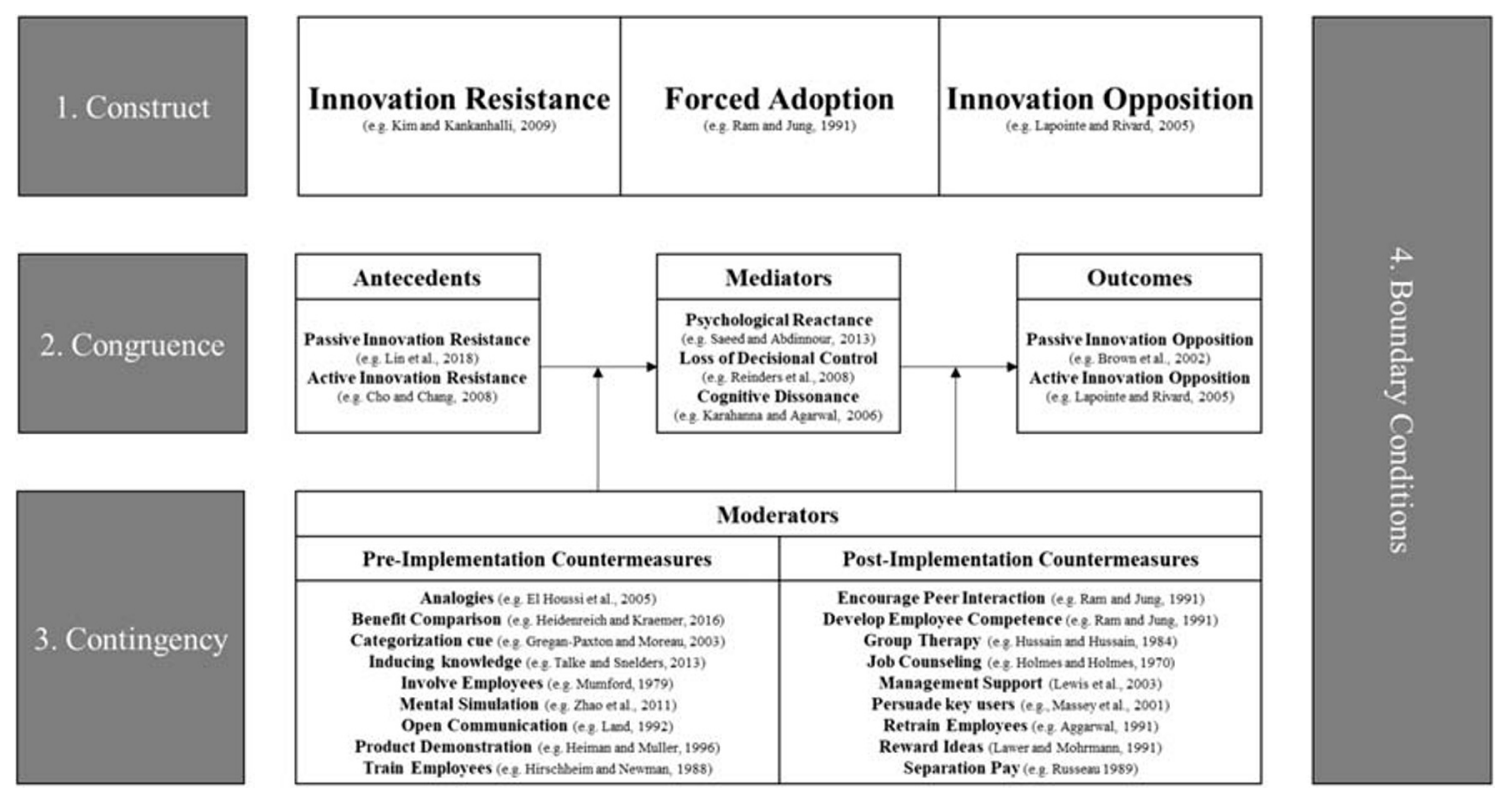

Fig. 3 Potential research avenues for future research 
identifying further opposition behaviors, expand our typology and the integrity of our innovation decision model.

\section{Addressing research gaps related to congruence}

While our innovation decision model of the secondary adoption process provides first theoretical insights into the decision-making process of organization members in mandated adoption contexts, an empirical validation of the process structure as well as of the assumed relationships is still to be carried out. Future research may use the model as a conceptual framework to address the following gaps.

First, while we use the innovation decision model to describe the transformational mechanisms that lead from passive and active innovation resistance to behavioral consequences, empirical evidence for the allocation of outcomes to the process stages is lacking. Hence, gaining a deeper understanding of how employees process information to evaluate an innovation in mandated contexts could provide interesting insights. Similar to the study of Olshavsky and Spreng (1996) on consumer decision-making processes, future organizational studies might utilize qualitative approaches, such as analyzing cases in which employees are confronted with several work-related innovations. Observing the information-processing steps that employees use to evaluate new work routines would empirically validate our suggestion that the secondary adoption process consists of three stages. Furthermore, future studies could evaluate whether passive and active resistance primarily emerge in the knowledge and persuasion stage as suggested. Likewise, future studies could determine in which stages different types of opposition behavior, namely, passive and active opposition as well as their covert and overt forms, emerge and are most often observed. These findings would add to the innovation decision model and enhance its external validity.

Second, based on the findings of the systematic literature review, we draw on theory related to psychological reactance (Saeed and Abdinnour 2013), decisional control (Reinders et al. 2008), and cognitive dissonance (Karahanna and Agarwal 2006) to provide theoretical rationales to explain how passive innovation resistance and active innovation resistance trigger passive opposition behavior and active opposition behavior due to forced adoption. While our innovation decision model thus provides the first theoretical insights into the relationships among the core constructs in mandatory adoption scenarios, namely, innovation resistance, forced adoption and innovation opposition, empirical evidence of the proposed relationships is still lacking. Hence, future research might empirically examine the proposed conceptual process model to validate our propositions. Furthermore, a systematic, empirical examination that evaluates the relative importance and possible interaction effects of different adopter-, situation-, or innovation-specific factors on negative outcomes throughout the different stages of the secondary adoption process in mandatory settings is still lacking. Examining the relative importance of these factors seems necessary since each factor's impact likely varies across the stages of the adoption process (Talke and Heidenreich 2014). The findings of Meyer and Goes (1988) show that innovationspecific factors like perceived complexity play an important role in the early stages of the adoption process, whereas relative advantage (value barrier) is more important in later stages (Frambach and Schillewaert 2002; Labay and Kinnear 1981). Consequently, future research might use longitudinal data to determine the relative importance of the constructs and their antecedents throughout the stages of our innovation decision model.

Third, numerous studies have already dealt with various forms of active and passive opposition behavior (Laumer and Eckhardt 2012). However, these studies mostly focus on specific types of opposition behavior at one point in time. The chain of effects of forced adoption that is laid out in our innovation decision model suggests that opposition behavior can change over time. More specifically, this behavior can evolve from passive forms, such as dissatisfaction, to active forms, such as mobbing, and they might become more extreme over time. Past research confirms that the permanent dissatisfaction of organization members is a core reason for job terminations (Chen et al. 2011; Griffeth et al. 2000) and that the loss of key personnel can pose a substantial threat to the financial situation of organizations (Subramony and Holtom 2012). Hence, both human resource management and internal marketing would benefit from a better understanding of the interdependencies between various forms of opposition behavior and changes that occur over time. Again, findings from future longitudinal studies would help address this research gap and thereby help companies develop de-escalating measures to prevent the increasingly detrimental effects for the organization that occur during secondary adoption processes.

\section{Addressing research gaps related to contingency}

Our innovation decision model of the secondary adoption process depicts how innovation resistance in mandated contexts triggers cognitive dissonance via psychological reactance and the loss of decisional control, which ultimately leads to opposition behavior. The strength of the assumed effects, however, is unclear and may depend on additional variables (Hwang et al. 2016). Hence, future research might take on a contingency perspective and evaluate how the assumed relationships are affected by different moderators. Since reducing innovation failure due to forced adoption is often deemed as a research priority (Cho and Chang 2008; Haddara and Moen 
2017), we focus on moderators that might buffer negative consequences of mandated usage. Such moderators should be effective in either reducing the negative effects of passive and active innovation resistance on cognitive dissonance or reducing the negative effects of cognitive dissonance on innovation opposition. Consumer behavior research already provides evidence on the effectiveness of a wide range of instruments for increasing the probability of adoption (e.g., Dahl et al. 1999; El Houssi et al. 2005). Due to the peculiarities of organizational contexts, however, these instruments may not be readily adopted. For example, sales discounts or guarantees are popular instruments used to reduce consumers' initial innovation resistance. However, service promises like product training, installation assistance, fast repair or replacement services are likely to be more effective in organizational contexts, since organizational members are most likely to fear an increased workload. Hence, testing the effectiveness of preimplementation measures to counter the negative effects of passive and active innovation resistance and postimplementation countermeasures to reduce the negative effects of cognitive dissonance would be promising avenues for future research (e.g., Samhan 2018).

With respect to pre-implementation countermeasures, future research might test the effectiveness of several internal marketing measures in innovation announcements (Piercy and Morgan 1991; Varey 1995). Previous research in consumer contexts suggests that mental simulation (Zhao et al. 2011) or analogies (El Houssi et al. 2005) may also help employees understand the compatibility of the new working routine with familiar practices (Heidenreich and Kraemer 2016). This should help employees align the innovation with existing work patterns, thus reducing the negative effects of passive innovation resistance. Likewise, future research could test the effectiveness of benefit comparison (Heidenreich and Kraemer 2016) or inducing knowledge (Talke and Snelders 2013) in innovation announcements to highlight the benefits of the innovation over the established options in the company. This should enhance employee perceptions of the relative advantages of the innovation and thus attenuate active innovation resistance. Finally, product demonstration seems to be an effective countermeasure as well (Heiman and Muller 1996). Ram and Jung (1991) find that individuals who were able to test an innovation shortly after its announcement exhibited significantly lower levels of active innovation resistance. Besides pre-implementation countermeasures focusing on the innovation itself, future research might also test measures focusing on the employee such as open communication (Klaus and Blanton 2010) and trainings (Hirschheim and Newman 1988) reduce employee-internal barriers to change and the resulting negative effects of passive innovation resistance. In addition to offering testing facilities and trainings early in the implementation process, measures such as the integration of organization members in selecting, adapting and implementing an innovation (Mumford 1979) might also help reduce negative effects of a forced adoption.

With respect to postimplementation countermeasures, future research might test the effectiveness of peer interaction (Ram and Jung 1991), group therapy (Hussain and Hussain 1984) and job counseling (Holmes and Holmes 1970) as alternative routes to reduce cognitive dissonance. Previous studies show that colleagues' opinions have a salient social influence (Lewis et al. 2003), such that employees have the tendency to conform to their colleagues' opinions (Ajzen 2002; Lewis et al. 2003) due to their need for social companionship (Kim and Kankanhalli 2009). Hence, future research might test the effectiveness of employing key users to spread positive word-of-mouth regarding the innovation (Massey et al. 2001) to decrease the negative effects of cognitive dissonance after implementation. Likewise, companies might use leaders in internal marketing to instill into followers a sense of oneness with the objectives of the innovation implementation process (Wieseke et al. 2009). Future research may also investigate how offering different incentives to use an innovation can reduce opposition behavior. For IS systems, Hirschheim and Newman (1988) show that organizational guidance and incentives throughout the implementation process can reduce negative reactions to forced innovation adoption. Following the findings of Kim and Kankanhalli (2009), future research might also investigate organizational measures that can be used to develop competences (Ram and Jung 1991), which can ease individual adaptation to new working routines, thus reducing the negative effects of cognitive dissonance. Several studies empirically support the importance of providing trainings for organization members (Igbaria et al. 1996; Jasperson et al. 2005). However, there is still a need for empirical investigations into the relative impact of such measures on preventing opposition behavior due to a reduction of detrimental effects of cognitive dissonance.

\section{Addressing research gaps related to boundary conditions}

Since most studies on innovation adoption in organizations generally decouple the secondary adoption process from the primary adoption process, the mandated context and other boundary conditions remain neglected. In this respect, prior research highlights that managerial interventions (Rumelt, 1995) and expectations evoked during the primary adoption process by the decision makers (Davis et al. 1989) act as important boundary conditions for the secondary adoption process. Accordingly, Gallivan (2001) classifies managerial interventions and subjective norms as two of three important categories of boundary conditions for the secondary adoption process and identifies organizational attributes as the third category. While such boundary conditions unlikely change the principal structure of our proposed secondary adoption 
process, they may influence the amount of initial resistance generated and thus strongly determine whether a mandated usage transforms into symbolic or forced adoption.

Several studies show that the implementation climate (Klein and Sorra 1996; Schalk et al. 1998) and the organizational culture (Johansson et al. 2014; Oreg 2003) strongly affect employee responses to innovations. More specifically, employees in younger companies, especially start-up firms with an entrepreneurial culture, may be familiar with continuous change, have no issue with mandated adoption and even embrace change. However, employees in established firms with a conservative culture may be much harder to convince to use an innovation, and thus, the effects of mandated usage might become even more severe. This finding seems to be related to firm age rather than to the age of the individual employee. The findings of Kunze et al. (2013) at least show that older employees were less resistant towards IT innovations than their younger colleagues. Similarly, differences in social and national culture were also shown to influence individual working in companies and their responses to innovations (Jassawalla and Sashittal 2002; Uğur 2017). The amount of initial resistance generated and thus the probability that a mandated usage transforms into forced adoption might principally be much higher in countries like Greece with high uncertainty avoidance (Tsatsou 2012) compared to countries like Denmark with low uncertainty avoidance (Peters and Den Dulk 2003). In addition to factors related to cultural attributes, managerial interventions applied by the authority decision unit can also have similar effects. For instance, the amount of resources assigned to support the implementation of the innovation might strongly determine whether resistance emerges during secondary adoption (Rumelt 1995). In addition, the communication measures within internal marketing applied by the authority decision unit might have similar effects since they strongly determine the employees' expectations and perception of the innovation (Hutt et al. 1995). If little information is provided, a mandated adoption might appear as a surprise, and changes likely are perceived more radical than they are. As confirmed by prior research, changes that are perceived as radical evoke stronger negative reactions with respect to innovation resistance than incremental innovations (Heidenreich et al. 2016).

It thus can be concluded that the principal cause and effect relationships in the secondary adoption processes should be largely independent of the boundary conditions. However, the magnitude of employee resistance might vary for different boundary conditions. As a consequence, boundary conditions might determine whether an employee develops cognitive dissonance and engages in opposition behavior as the result of perceived forced adoption. Future studies may draw on published reviews of potential boundary conditions (Orlikowski 1993; Pardo del Val and Martínez Fuentes 2003) and test whether the assumed relationships in each process stage might vary in their magnitude under different boundary conditions. Based on the results, it may become easier to identify organizational settings in which it is more likely that severe problems will arise due to forced adoption.

Furthermore, future research might focus on interdependencies between the primary and the secondary adoption process. Anecdotal evidence implies that high levels of employee resistance and extreme forms of opposition behavior let organizations revise the original outcome of the primary adoption process (Bhattacherjee et al. 2013). Future research might thus take our innovation decision model of the secondary adoption process and connect it with established innovation decision models for the primary adoption process to shed light on the reciprocal effects of their intersection.

\section{Conclusion}

The organizational implementation of innovations in mandatory contexts and the resulting employee resistance and opposition caused by forced adoption have become prominent topics in organizational research in recent years (Cho and Chang 2008; Hwang et al. 2016; Kumar et al. 2018). While employee adoption of innovations in organizations is undoubtedly related to consumer adoption of new products, both research streams thus far lack explicit integration. Perhaps as a consequence of this lack of anchoring in established concepts of consumer adoption theory, our literature review reveals considerable conceptual ambiguity and a lack of theoretical foundations with respect to the core constructs of forced adoption in organizations. Furthermore, our literature review underlines the need for synthesizing and integrating the scattered findings of disconnected research efforts in mandated usage contexts to establish a common theoretical ground on which future research on forced adoption may start. To help fill this gap, we develop an innovation decision model of the secondary adoption process that illustrates how innovation adoption proceeds for individuals in organizations, why and at which stage negative outcomes emerge, and how these outcomes promote different forms of innovation opposition. Based on this model, we identify important avenues for future research and show how the conceptual clarification and cumulative empirical work of future studies might contribute to our current knowledge and thereby advance the development of theory on forced adoption in organizations. We hope that the present article not only provides a comprehensive overview of past research activities in this domain, but also lays out viable research avenues that future scholars in the domain of forced adoption find attractive.

Funding Information Open Access funding provided by Projekt DEAL. 


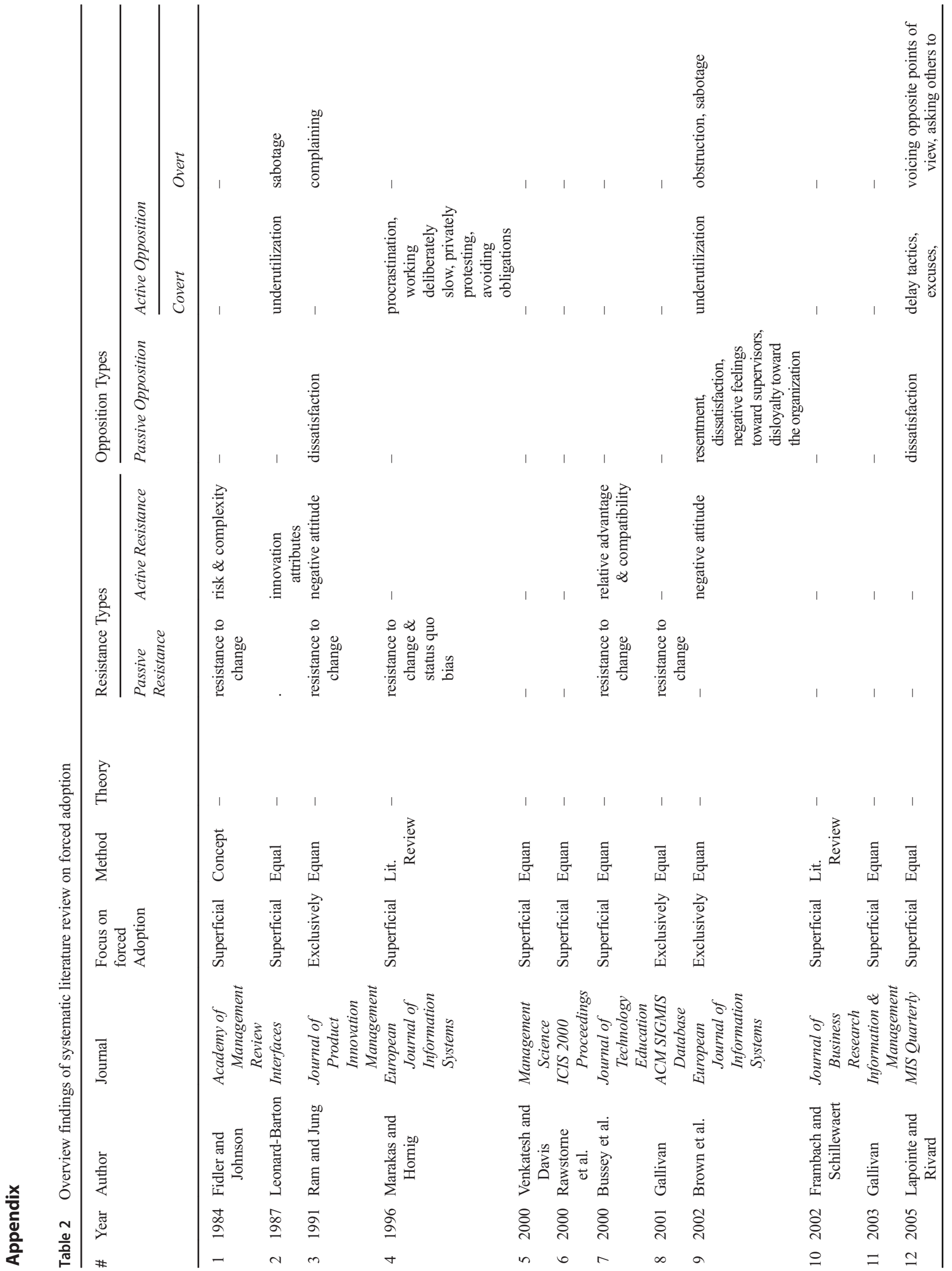




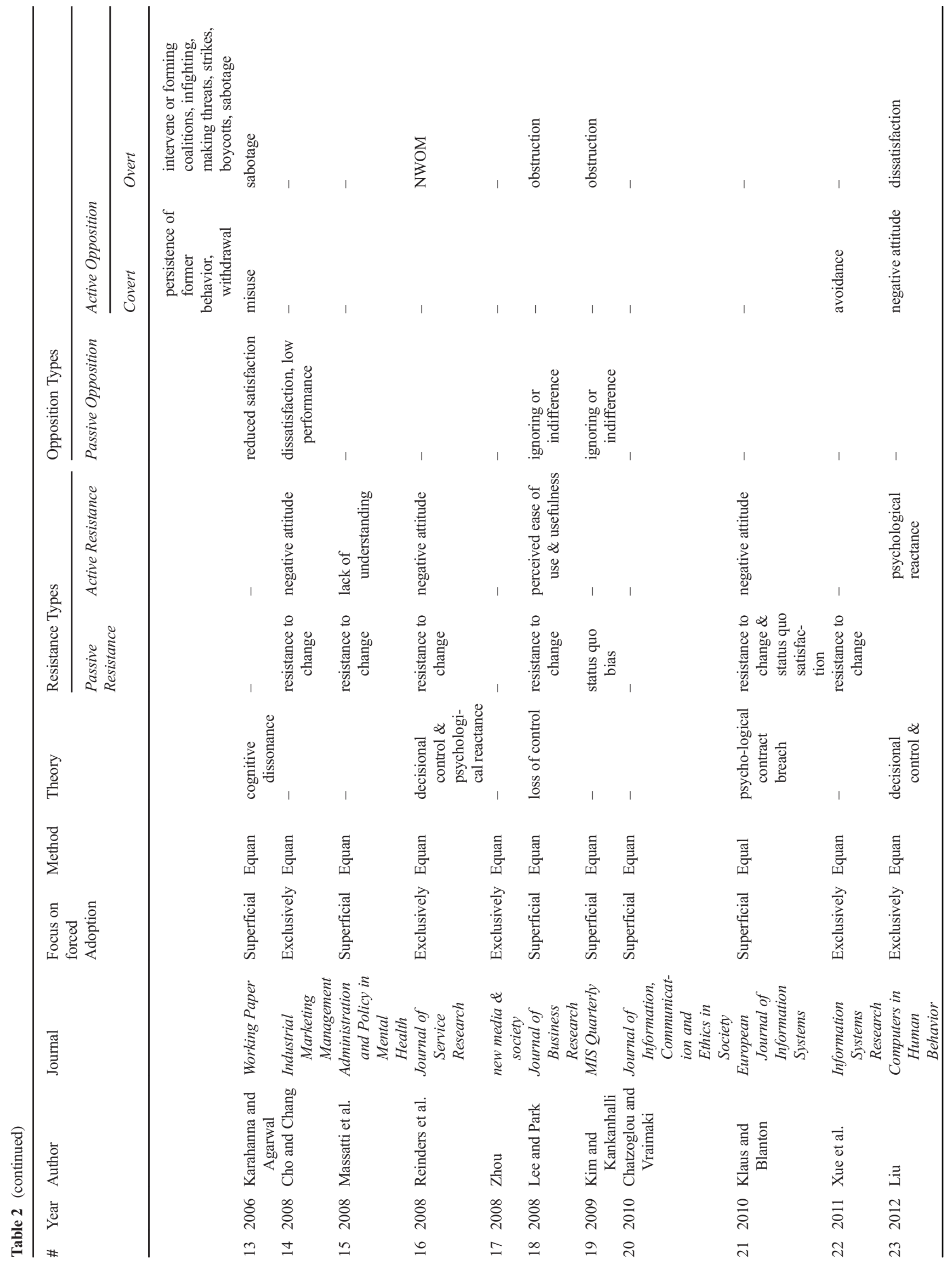




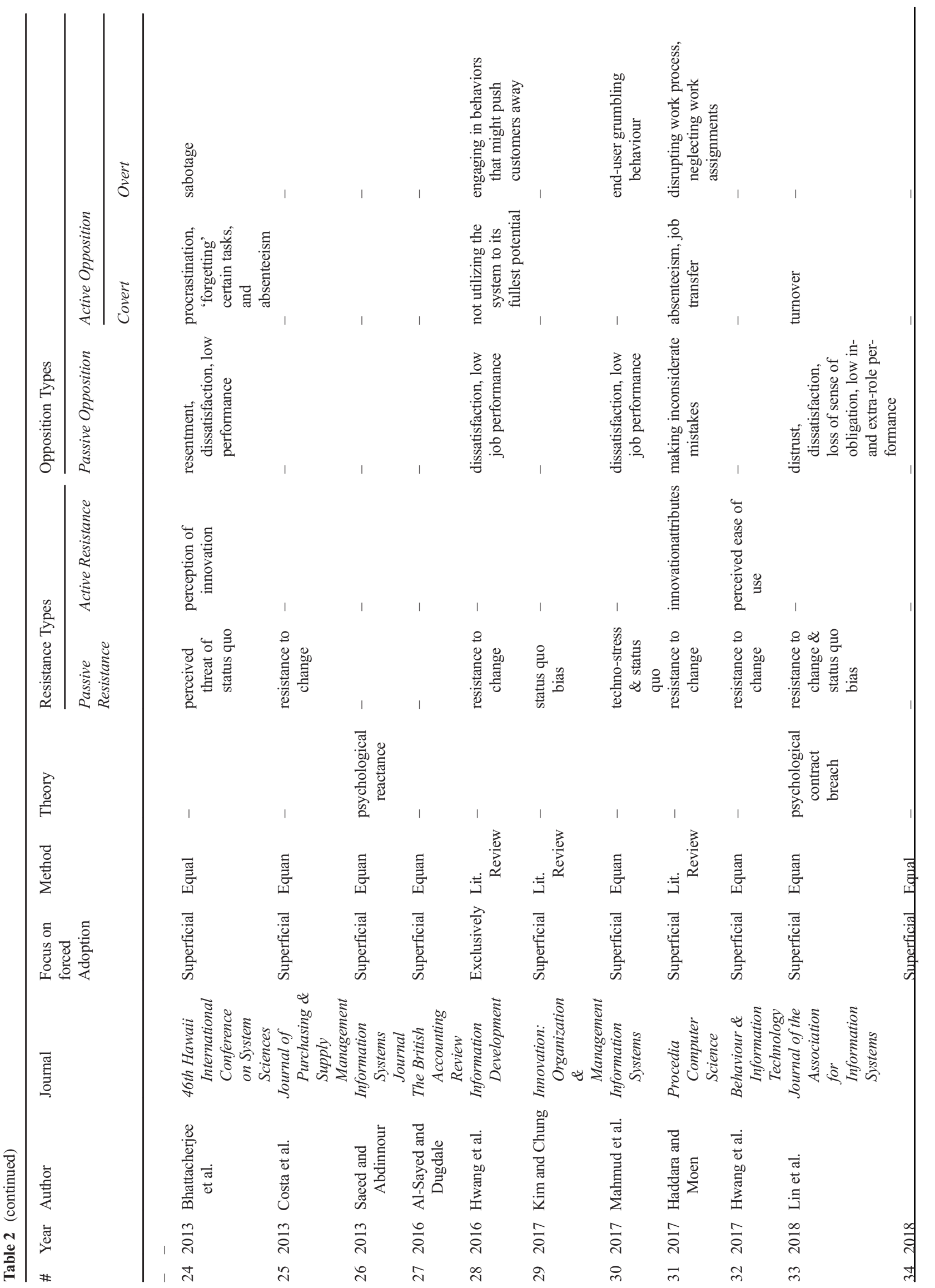




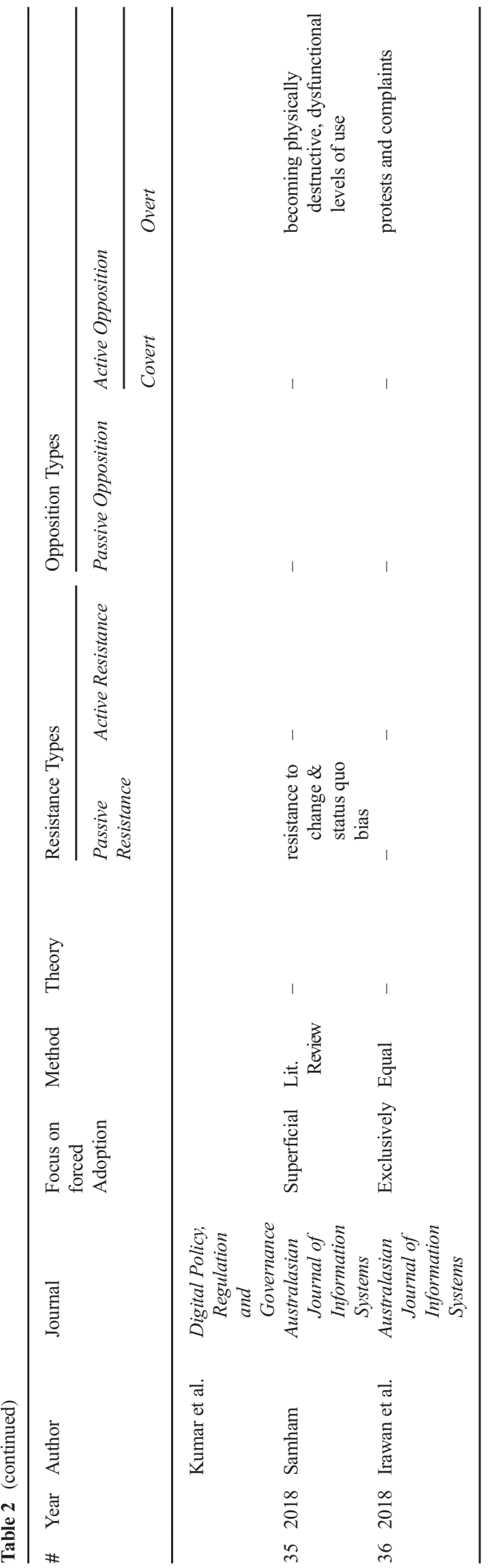

Open Access This article is licensed under a Creative Commons Attribution 4.0 International License, which permits use, sharing, adaptation, distribution and reproduction in any medium or format, as long as you give appropriate credit to the original author(s) and the source, provide a link to the Creative Commons licence, and indicate if changes were made. The images or other third party material in this article are included in the article's Creative Commons licence, unless indicated otherwise in a credit line to the material. If material is not included in the article's Creative Commons licence and your intended use is not permitted by statutory regulation or exceeds the permitted use, you will need to obtain permission directly from the copyright holder. To view a copy of this licence, visit http://creativecommons.org/licenses/by/4.0/.

\section{References}

Abramson, L. Y., Seligman, M. E., \& Teasdale, J. D. (1978). Learned helplessness in humans: Critique and reformulation. Journal of Abnormal Psychology, 87(1), 49-74.

Ajzen, I. (2002). Perceived behavioral control, self-efficacy, locus of control, and the theory of planned behavior. Journal of Applied Social Psychology, 32(4), 665-683.

Ajzen, I., \& Madden, T. J. (1986). Prediction of goal directed behavior: Attitudes, intentions and perceived behavioral control. Journal of Experimental Social Psychology, 22, 453-474.

Al-Sayed, M., \& Dugdale, D. (2016). Activity-based innovations in the UK manufacturing sector: Extent, adoption process patterns and contingency factors. The British Accounting Review, 48(1), 38-58.

Andrews, G., Singh, M., \& Bond, M. (1993). The defense style questionnaire. The Journal of Nervous and Mental Disease, 181(4), 246256.

Aronson, E. (1969). The theory of cognitive dissonance: A current perspective. In L. Berkowitz (Ed.), Advances in experimental social psychology (4th ed., pp. 1-34). New York: Academic Press.

Arts, J. W. C., Frambach, R. T., \& Bijmolt, T. H. A. (2011). Generalizations on consumer innovation adoption: A metaanalysis on drivers of intention and behavior. International Journal of Research in Marketing, 28(2), 134-144.

Bagozzi, R. P., \& Lee, K.-H. (1999). Consumer resistance to, and acceptance of, innovations. Advances in Consumer Research, 26(1), 218 225.

Barr, P. S., Stimpert, J. L., \& Huff, A. S. (1992). Cognitive change, strategic action, and organizational renewal. Strategic Management Journal, 13(S1), 15-36.

Barreto, I. (2010). Dynamic capabilities: A review of past research and an agenda for the future. Journal of Management, 36(1), 256-280.

Bartels, J., \& Reinders, M. J. (2011). Consumer innovativeness and its correlates: A propositional inventory for future research. Journal of Business Research, 64(6), 601-609.

Bhattacherjee, A., Davis, C., \& Hikmet, N. (2013). Physician reactions to healthcare IT: An activity-theoretic analysis. In System Sciences (HICSS), 2013 46th Hawaii International Conference on (pp. 2545-2554). IEEE.

Botti, S., McGill, A. L., \& Iyengar, S. S. (2003). Preference for control and its effect on the evaluation of consumption experiences. $A C R$ North American Advances.

Bovey, W. H., \& Hede, A. (2001). Resistance to organizational change: The role of defense mechanisms. Journal of Managerial Psychology, 16(7), 534-548.

Brehm, J. W. (1966). A theory of psychological reactance.

Brown, S. A., Massey, A. P., Montoya-Weiss, M. M., \& Burkman, J. R. (2002). Do I really have to? User acceptance of mandated technology. European Journal of Information Systems, 11(4), 283-295. 
Burgelman, R. A. (1983). A process model of internal corporate venturing in the diversified major firm. Administrative Science Quarterly, $28,223-244$.

Chen, G., Ployhart, R. E., Thomas, H. C., Anderson, N., \& Bliese, P. D. (2011). The power of momentum: A new model of dynamic relationships between job satisfaction change and turnover intentions. Academy of Management Journal, 54(1), 159-181.

Cho, S. D., \& Chang, D. R. (2008). Salesperson's innovation resistance and job satisfaction in intra-organizational diffusion of sales force automation technologies: The case of South Korea. Industrial Marketing Management, 37(7), 841-847.

Choi, M. (2011). Employees' attitudes toward organizational change: A literature review. Human Resource Management, 50(4), 479-500.

Claudy, M. C., Garcia, R., \& O’Driscoll, A. (2015). Consumer resistance to innovation - A behavioral reasoning perspective. Journal of the Academy of Marketing Science, 43(4), 528-544.

Clee, M. A., \& Wicklund, R. A. (1980). Consumer behavior and psychological reactance. Journal of Consumer Research, 6(4), 389-405.

Cooper, R. B., \& Zmud, R. W. (1990). Information technology implementation research: A technological diffusion approach. Management Science, 36(2), 123-139.

Costa, A. A., Arantes, A., \& Tavares, L. V. (2013). Evidence of the impacts of public e-procurement: The Portuguese experience. Journal of Purchasing and Supply Management, 19(4), 238-246.

Dahl, D. W., Chattopadhyay, A., \& Gorn, G. J. (1999). The use of visual mental imagery in new product design. Journal of Marketing Research, 36(2), 18-28.

Davis, F. D., Bagozzi, R. P., \& Warshaw, P. R. (1989). User acceptance of computer technology: A comparison of two theoretical models. Management Science, 35(8), 982-1003.

De Board, R. (2014). The psychoanalysis of organizations: A psychoanalytic approach to behaviour in groups and organizations. London: Routledge.

Deci, E. L., \& Ryan, R. M. (2000). The" what" and" why" of goal pursuits: Human needs and the self-determination of behavior. Psychological Inquiry, 11(4), 227-268.

Dubin, R. (1978). Theory building. New York: Free Press.

El Houssi, A. A., Morel, K. P., \& Hultink, E. J. (2005). Effectively communicating new product benefits to consumers: The use of analogy versus literal similarity. Advances in Consumer Research, 32(1), 1-6.

Faragher, E. B., Cass, M., \& Cooper, C. L. (2005). The relationship between job satisfaction and health: A meta-analysis. Occupational \& Environmental Medicine, 62(2), 105-112.

Festinger, L. (1957). A theory of cognitive dissonance. Evanston: Row, Peterson and Company.

Fidler, L. A., \& Johnson, J. D. (1984). Communication and innovation implementation. Academy of Management Review, 9(4), 704-711.

Foss, N. J., \& Saebi, T. (2017). Fifteen years of research on business model innovation: How far have we come, and where should we go? Journal of Management, 43(1), 200-227.

Frambach, R. T., \& Schillewaert, N. (2002). Organizational innovation adoption: A multi-level framework of determinants and opportunities for future research. Journal of Business Research, 55, 163-176.

Gallivan, M. J. (2001). Organizational adoption and assimilation of complex technological innovations: Development and application of a new framework. ACM SIGMIS Database: the DATABASE for Advances in Information Systems, 32(3), 51-85.

Gersick, C. J., \& Hackman, J. R. (1990). Habitual routines in taskperforming groups. Organizational Behavior and Human Decision Processes, 47(1), 65-97.

Griffeth, R. W., Hom, P. W., \& Gaertner, S. (2000). A meta-analysis of antecedents and correlates of employee turnover: Update, moderator tests, and research implications for the next millennium. Journal of Management, 26(3), 463-488.
Haddara, M., \& Hetlevik, T. (2016). Investigating the effectiveness of traditional support Structures \& Self-organizing Entities within the ERP shakedown phase. Procedia Computer Science, 100, 507-516.

Haddara, M., \& Moen, H. (2017). User resistance in ERP implementations: A literature review. Procedia Computer Science, 121, 859-865.

Heidenreich, S., \& Handrich, M. (2015). What about passive innovation resistance? Investigating adoption-related behavior from a resistance perspective. Journal of Product Innovation Management, 32(6), 878-903.

Heidenreich, S., \& Kraemer, T. (2015). Passive innovation resistance: The curse of innovation? Investigating consequences for innovative consumer behavior. Journal of Economic Psychology, 51, 134-151.

Heidenreich, S., \& Kraemer, T. (2016). Innovations - Doomed to fail? Investigating strategies to overcome passive innovation resistance. Journal of Product Innovation Management, 33(3), 277-297.

Heidenreich, S., \& Spieth, P. (2013). Why innovations fail - the case of passive and active innovation resistance. International Journal of Innovation Management, 17(5), 1-42.

Heidenreich, S., Kraemer, T., \& Handrich, M. (2016). Satisfied and unwilling: Exploring cognitive and situational resistance to innovations. Journal of Business Research, 69(7), 2440-2447.

Heiman, A., \& Muller, E. (1996). Using demonstration to increase new product acceptance: Controlling demonstration time. Journal of Marketing Research, 33(6), 422-430.

Herold, D. M., Fedor, D. B., \& Caldwell, S. D. (2007). Beyond change management: A multilevel investigation of contextual and personal influences on employees' commitment to change. Journal of Applied Psychology, 92(4), 942-951.

Hirschheim, R., \& Newman, M. (1988). Information systems and user resistance: Theory and practice. Computer Journal, 31(5), 398-408.

Holmes, T. S., \& Holmes, T. H. (1970). Short-term intrusions into the life style routine. Journal of Psychosomatic Research, 14(2), 121-132.

Hui, M. K., \& Toffoli, R. (2002). Perceived control and consumer attribution for the service encounter. Journal of Applied Social Psychology, 32(9), 1825-1844.

Hussain, D., \& Hussain, K. M. (1984). Information resource management. Richard d Irwin.

Hutt, M. D., Walker, B. A., \& Frankwick, G. L. (1995). Hurdle the crossfunctional barriers to strategic change. MIT Sloan Management Review, 36(3), 22.

Hwang, Y., Al-Arabiat, M., \& Shin, D. H. (2016). Understanding technology acceptance in a mandatory environment: A literature review. Information Development, 32(4), 1266-1283.

Hwang, Y., Chung, J. Y., Shin, D. H., \& Lee, Y. (2017). An empirical study on the integrative pre-implementation model of technology acceptance in a mandatory environment. Behaviour \& Information Technology, 36(8), 861-874.

Igbaria, M., Parasuraman, S., \& Baroudi, J. (1996). A motivational model of microcomputer usage. Journal of Management Information Systems, 13(1), 127-143.

Im, S., Bayus, B. L., \& Mason, C. H. (2003). An empirical study of innate consumer innovativeness, personal characteristics, and new-product adoption behavior. Journal of the Academy of Marketing Science, 31(1), 61-73.

Irawan, S., Foster, S., \& Tanner, K. (2018). The mandated adoption and implementation of an academic information system: Empirical evidence from an Indonesian University. Australasian Journal of Information Systems, 22.

Jahanmir, S. F., \& Cavadas, J. (2018). Factors affecting late adoption of digital innovations. Journal of Business Research, 88, 337-343.

Jasperson, J., Carter, P., \& Zmud, R. (2005). A comprehensive conceptualization of the postadoptive behaviors associated with IT-enabled work systems. MIS Quarterly, 29(3), 525-557. 
Jassawalla, A. R., \& Sashittal, H. C. (2002). Cultures that support product-innovation processes. Academy of Management Perspectives, 16(3), 42-54.

Joachim, V., Spieth, P., \& Heidenreich, S. (2018). Active innovation resistance: An empirical study on functional and psychological barriers to innovation adoption in different contexts. Industrial Marketing Management, 71, 95-107.

Johansson, C., Åström, S., Kauffeldt, A., Helldin, L., \& Carlström, E. (2014). Culture as a predictor of resistance to change: A study of competing values in a psychiatric nursing context. Health Policy, $114(2-3), 156-162$.

Johnson, D. S., Bardhi, F., \& Dunn, D. T. (2008). Understanding how technology paradoxes affect customer satisfaction with self-service technology: The role of performance ambiguity and trust in technology. Psychology \& Marketing, 25(5), 416-443.

Jones, R. A., Jimmieson, N. L., \& Griffiths, A. (2005). The impact of organizational culture and reshaping capabilities on change implementation success: The mediating role of readiness for change. Journal of Management Studies, 42(2), 361-386.

Karahanna, E., \& Agarwal, R. (2006). When the spirit is willing: Symbolic adoption and technology exploration. Athens: University of Georgia.

Keats, B. W., \& Bracker, J. S. (1988). Toward a theory of small firm performance: A conceptual model. American Journal of Small Business, 12(4), 41-58.

Kim, J. S., \& Chung, G. H. (2017). Implementing innovations within organizations: A systematic review and research agenda. Innovation, 19(3), 372-399.

Kim, H.-W., \& Kankanhalli, A. (2009). Investigating user resistance to information systems implementation: A status quo bias perspective. MIS Quarterly, 33(3), 567-582.

Kimberling, E. (2014). 2014 ERP report. Denver: Panorama Consulting Solutions.

Kishore, R., \& McLean, E. R. (2007). Reconceptualizing innovation compatibility as organizational alignment in secondary IT adoption contexts: An investigation of software reuse infusion. IEEE Transactions on Engineering Management, 54(4), 756-775.

Klaus, T., \& Blanton, J. E. (2010). User resistance determinants and the psychological contract in enterprise system implementations. European Journal of Information Systems, 19(6), 625-636.

Klein, K. J., \& Sorra, J. S. (1996). The challenge of innovation implementation. Academy of Management Review, 21(4), 1055-1080.

Klonglan, G. E., \& Coward, E. W. (1970). The concept of symbolic adoption: A suggested interpretation. Rural Sociology, 35(1), 77-83.

Kumar, R., Sachan, A., Mukherjee, A., \& Kumar, R. (2018). Factors influencing e-government adoption in India: A qualitative approach. Digital Policy, Regulation and Governance, 20(5), 413-433.

Kunze, F., Boehm, S., \& Bruch, H. (2013). Age, resistance to change, and job performance. Journal of Managerial Psychology, 28(7/8), 741-760.

Labay, D. G., \& Kinnear, T. C. (1981). Exploring the consumer decision process in the adoption of solar energy systems. Journal of Consumer Research, 8(3), 271-278.

Labrecque, J. S., Wood, W., Neal, D. T., \& Harrington, N. (2016). Habit slips: When consumers unintentionally resist new products. Journal of the Academy of Marketing Science, 45, 119-133.

Lapointe, L., \& Rivard, S. (2005). A multilevel model of resistance to information technology implementation. MIS Quarterly, 29(3), 461-491.

Laukkanen, T. (2016). Consumer adoption versus rejection decisions in seemingly similar service innovations: The case of the internet and mobile banking. Journal of Business Research, 69(7), 2432-2439.

Laukkanen, P., Sinkkonen, S., \& Laukkanen, T. (2008). Consumer resistance to internet banking: Postponers, opponents and rejectors. International Journal of Bank Marketing, 26(1), 440-455.

Laumer, S., \& Eckhardt, A. (2012). Why do people reject technologies: A review of user resistance theories. In Y. K. Dwivedi, M. R. Wade, \& S.
L. Schneberger (Eds.), Information systems theory - explaining and predicting our digital society (1st ed., pp. 63-86). New York: Springer.

Lehmann, D. R., \& Parker, J. R. (2017). Disadoption. AMS Review, 7(12), 36-51.

Leonard, N. H., Beauvais, L. L., \& Scholl, R. W. (1999). Work motivation: The incorporation of self-concept-based processes. Human Relations, 52(8), 969-998.

Leonard-Barton, D. (1987). Implementing structured software methodologies: A case of innovation in process technology. Interfaces, 17(3), 6-17.

Leonard-Barton, D., \& Deschamps, I. (1988). Managerial influence in the implementation of new technology. Management Science, 34(10), $1252-1265$.

Lewis, W., Agarwal, R., \& Sambamurthy, V. (2003). Sources of influence on beliefs about information technology use: An empirical study of knowledge workers. MIS Quarterly, 27(4), 657-678.

Lin, T. C., Huang, S. L., \& Chiang, S. C. (2018). User resistance to the implementation of information systems: A psychological contract breach perspective. Journal of the Association for Information Systems, 19(4), 306-332.

Liu, S. (2012). The impact of forced use on customer adoption of self-service technologies. Computers in Human Behavior, 28(4), 1194-1201.

Mahmud, I., Ramayah, T., \& Kurnia, S. (2017). To use or not to use: Modelling end user grumbling as user resistance in preimplementation stage of enterprise resource planning system. Information Systems, 69, 164-179.

Mallen, G. L. (1970). Control theory and decision making in Organisations a reconnaissance. Measurement and Control, 3(3), T46-T48.

Marakas, G. M., \& Hornik, S. (1996). Passive resistance misuse: Overt support and covert recalcitrance in is implementation. European Journal of Information Systems, 5(3), 208-219.

Markus, M. L. (1983). Power, politics, and MIS implementation. Communications of the ACM, 26(6), 430-444.

Massey, A. P., Montoya-Weiss, M. M., \& Brown, S. A. (2001). Reaping the benefits of innovative IT: The long and winding road. IEEE Transactions on Engineering Management, 48(3), 348-357.

Meyer, A. D., \& Goes, J. B. (1988). Organizational assimilation of innovations: A multilevel contextual analysis. Academy of Management Journal, 31(4), 897-923.

Mezias, S. J., \& Glynn, M. A. (1993). The three faces of corporate renewal: Institution, revolution, and evolution. Strategic Management Journal, 14(2), 77-101.

Mumford, E. (1979). Human values and the introduction of technological change. Manchester Business School Review, 3(2), 13-17.

Nabih, M. I., Bloem, J. G., \& Poiesz, T. B. C. (1997). Conceptual issues in the study of innovation adoption behavior. Advances in Consumer Research, 24(1), 190-196.

Oldham, M., \& Kleiner, B. H. (1990). Understanding the nature and use of defense mechanisms in organisational life. Journal of Managerial Psychology, 5(5), 1-4.

Olshavsky, R. W., \& Spreng, R. A. (1996). An exploratory study of the innovation evaluation process. Journal of Product Innovation Management, 13(6), 512-529.

Oreg, S. (2003). Resistance to change: Developing an individual differences measure. Journal of Applied Psychology, 88(4), 680-693.

Orlikowski, W. J. (1993). CASE tools as organizational change: Investigating incremental and radical changes in systems development. MIS Quarterly, 309-340.

Pardo del Val, M., \& Martínez Fuentes, C. (2003). Resistance to change: A literature review and empirical study. Management Decision, 41(2), 148-155.

Perera, S., McKinnon, J. L., \& Harrison, G. L. (2003). Diffusion of transfer pricing innovation in the context of commercialization-A longitudinal case study of a government trading enterprise. Management Accounting Research, 14(2), 140-164. 
Peters, P., \& Den Dulk, L. (2003). Cross cultural differences in managers' support for home-based telework: A theoretical elaboration. International Journal of Cross Cultural Management, 3(3), 329-346.

Piderit, S. K. (2000). Rethinking resistance and recognizing ambivalence: A multidimensional view of attitudes toward an organizational change. Academy of Management Review, 25(4), 783-794.

Piercy, N., \& Morgan, N. (1991). Internal marketing-The missing half of the marketing programme. Long Range Planning, 24(2), 82-93.

Pohl, A. (1996). Leapfrogging bei technischen Innovationen: ein Erklärungsansatz auf Basis der Theorie des wahrgenommenen Risikos. Wiesbaden: Gabler.

Rafiq, M., \& Ahmed, P. K. (1993). The scope of internal marketing: Defining the boundary between marketing and human resource management. Journal of Marketing Management, 9(3), 219-232.

Raisian, K., \& Yahaya, J. (2014). Review paper: Critical factors of user resistance in post-ERP implementation within an organization. International Journal of Research in Social Sciences, 4(8), 14-24.

Ram, S., \& Jung, H.-S. (1991). "forced" adoption of innovations in organizations: Consequences and implications. Journal of Product Innovation Management, 8(2), 117-126.

Ram, S., \& Sheth, J. N. (1989). Consumer resistance to innovations: The marketing problem and its solutions. Journal of Consumer Marketing, 6(2), 5-14.

Rawstorne, P., Jayasuriya, R., \& Caputi, P. (2000). Issues in predicting and explaining usage behaviors with the technology acceptance model and the theory of planned behavior when usage is mandatory. ICIS 2000 Proceedings, 5.

Reinders, M. J., Dabholkar, P. A., \& Frambach, R. T. (2008). Consequences of forcing consumers to use technology-based selfservice. Journal of Service Research, 11(2), 107-123.

Rogers, E. M. (2003). Diffusion of innovations. New York: The Free Press.

Rumelt, R. P. (1995). Inertia and transformation. In Resource-based and evolutionary theories of the firm: Towards a synthesis (pp. 101132). Boston, MA: Springer.

Saeed, K. A., \& Abdinnour, S. (2013). Understanding post-adoption IS usage stages: An empirical assessment of self-service information systems. Information Systems Journal, 23(3), 219-244.

Samhan, B. (2018). Revisiting technology resistance: Current insights and future directions. Australasian Journal of Information Systems, 22.

Schalk, R., Campbell, J. W., \& Freese, C. (1998). Change and employee behaviour. Leadership \& Organization Development Journal, 19(3), 157-163.

Scholl, W. (1996). Effective teamwork - a theoretical model and a test in the field. In Witte, E. \& Davis, J. (Eds.), Understanding group behavior. Small group processes and inter-personal relations (Vol. 2, pp. 127-146). Hillsdale: Erlbaum.
Scholl, W. (1999). Restrictive control and information pathologies in organizations. Journal of Social Issues, 55, 101-118.

Subramony, M., \& Holtom, B. C. (2012). The long-term influence of service employee attrition on customer outcomes and profits. Journal of Service Research, 15(4), 460-473.

Talke, K., \& Heidenreich, S. (2014). How to overcome pro-change bias: Incorporating passive and active innovation resistance in innovation decision models. Journal of Product Innovation Management, 31(5), 894-907.

Talke, K., \& Snelders, D. (2013). Information in launch messages: Stimulating the adoption of new high-tech consumer products. Journal of Product Innovation Management, 30(4), 732-749.

Tatsuse, T., \& Sekine, M. (2013). Job dissatisfaction as a contributor to stress-related mental health problems among Japanese civil servants. Industrial Health, 51(3), 307-318.

Tornatzky, L. G., \& Klein, K. J. (1982). Innovation characteristics and innovation adoption-implementation: A meta-analysis of findings. IEEE Transactions on Engineering Management, 29(1), 28-45.

Tsatsou, P. (2012). The role of social culture in internet adoption in Greece: Unpacking "I don't want to use the internet" and frequency of use. The Information Society, 28(3), 174-188.

Uğur, N. G. (2017). Cultural differences and technology acceptance: A comparative study. Journal of Media Critiques, 3(11), 123-132.

Varey, R. J. (1995). Internal marketing: A review and some interdisciplinary research challenges. International Journal of Service Industry Management, 6(1), 40-63.

Venkatesh, V., \& Davis, F. D. (2000). A theoretical extension of the technology acceptance model: Four longitudinal field studies. Management Science, 46(2), 186-204.

Wieseke, J., Ahearne, M., Lam, S. K., \& Van Dick, R. (2009). The role of leaders in internal marketing. Journal of Marketing, 73(2), 123-145.

Winter, J. P. (1985). Getting your house in order with internal marketing: A marketing prerequisite. Health Marketing Quarterly, 3(1), 69-77.

Xue, Y., Liang, H., \& Wu, L. (2011). Punishment, justice, and compliance in mandatory IT settings. Information Systems Research, 22(2), 400-414.

Zaltman, G., \& Wallendorf, M. (1983). Consumer behavior: Basic findings and management implications. New York: John Wiley and Sons.

Zhao, M., Hoeffler, S., \& Zauberman, G. (2011). Mental simulation and product evaluation: The affective and cognitive dimensions of process versus outcome simulation. Journal of Marketing Research, 48(5), 827-839.

Publisher's note Springer Nature remains neutral with regard to jurisdictional claims in published maps and institutional affiliations. 